\title{
EARLY ONSET POSTDURAL PUNCTURE HEADACHE: A CASE REPORT
}

\author{
C. B. Sridhar ${ }^{1}$, K. Shoba ${ }^{2}$
}

\section{HOW TO CITE THIS ARTICLE:}

C. B. Sridhar, K. Shoba. "Early Onset Postdural Puncture Headache: A Case Report". Journal of Evolution of Medical and Dental Sciences 2015; Vol. 4, Issue 10, February 02; Page: 1699-1701,

DOI: $10.14260 /$ jemds $/ 2015 / 240$

ABSTRACT: Post-dural punture headache is known to occur within three days in ninety percent of patients. However early onset is very rare. Hence we report a case of early onset postdural puncture headache with a 26G Quincke's needle occuring within 1 hour of subarachnoid block.

KEYWORDS: Subarachnoid block, Quincke's needle, postdural puncture headache.

INTRODUCTION: Post-dural puncture headache is a common complication of subarachnoid block. The incidence varies from $2-40 \%$ depending on the size and type of needle used. The onset occurs within 24 hours in $65 \%$ of the patients and the duration of headache lasts for 1-12 days. In this article we report a case of early onset post-dural puncture headache with a 26G Quincke's needle occurring within 1 hour of subarachnoid block, which is very rare.

CASE REPORT: A 22years old female patient with no history of any medical illness was posted for fissurectomy under subarachnoid block. With the patient in sitting position and under aseptic precautions, a dural puncture was done in $\mathrm{L}_{3}-\mathrm{L}_{4}$ interspace with a 26G Quincke's needle with the bevel of the needle parallel to the dural fibres and $1.5 \mathrm{ml}$ of $0.5 \%$ bupivacaine heavy was given after clear flow of cerebrospinal fluid. Patient was placed in supine position after 15minutes. Level of sensory block was $\mathrm{T}_{12}$. Fissurectomy was performed in lithotomy position and the surgery lasted 20 minutes. Patient's vitals were normal during the intra-operative period. She was hydrated well.

Within one hour of spinal anaesthesia, she complained of severe headache. The headache was bilateral frontal and occipital and was aggravated by standing, coughing or straining. It was not associated with photophobia, diplopia, tinnitus, vertigo or nausea and vomiting. Headache was graded 8 on Visual Analogue scale.

As she had no past history of migraine or cluster headache, CT Brain was taken which was normal. The diagnosis of post-dural puncture headache was considered as patient had postural headache.

Patient was started on supportive treatment with bed rest, paracetamol infusion, adequate hydration with IV fluids and tramadol injection. Symptoms reduced slowly. Supportive treatment was continued for the next three days.

Patient was ambulated after three day. Patient had no complain of headache hence further management with epidural blood patch was not considered.

DISCUSSION: Post-dural puncture headache is caused by excessive leak of cerebrospinal fluid from the dural puncture site. Reflex vasodilatation of meningeal vessels due to lower cerebrospinal fluid pressure or traction on pain sensitive intracranial structures could be the cause for post-dural punture headache. ${ }^{1}$ 
The onset of headache occurs within the first 3 days in ninety percent of patients and within 24 hours in $65 \%$ of the patients. ${ }^{2}$ Early onset is very rare. Just one case has been reported with an onset as early as 20 minutes. $^{3}$ This is the second case with onset of headache within one hour. However the diagnosis can only be confirmed after ruling out subdural/ intracranial haemorrage, central venous thrombosis, pre-existing tumours and pneumocephalus with CT Brain. Postural headache is the diagnostic factor which goes in favour of post-punture headache. In patient with past history of migrane or sinus headache, the same should be ruled out first.

The incidence of post-dural punture headache is proportional to the size of the needle. It is 2$12 \%$ with a 26G Quincke needle. ${ }^{4}$ Perpendicular orientation of the bevel of spinal needle and Quincke type needle reduces the incidence further. In our patient though subarachnoid block was given with a 26G Quincke's needle with the bevel directed parallel to the dural fibres in a single attempt, postdural puncture headache was present within 1 hour. ${ }^{4}$

Post punture headache is known to occur more frequently in young, with low body mass index and in women. ${ }^{5}$

Eighty five percent of post-dural punture headache recover spontaneously with no treatment. Supportive treatment like bed rest, rehydration, acetaminophen, non-steroidal anti-inflammatory drugs, opiods and antiemetics will help in controlling symptoms during the recovery phase. For patients with headache not reducing with supportive treatment epidural blood patch is the gold standard treatment. Surgical closure of dural tear is the last option.

Untreated post punture headache can lead to intracranial complications like subdural haematoma, which are rare but life threatening. ${ }^{6}$

\section{REFERENCES:}

1. Ghaleb A, Khorasani A, Mangar D. Post-dural punture headache. Int J Gen Med.2012; 5: 45-51.

2. Lybecker H,Djernes M, Schmidt JF. Postdural punture headache (PDPH): onset, duration, severity, and associated symptoms. Analysis of 75 consecutive patients with PDPH. Acta anaesthesiol scand. 1995 Jul; 39 (5): 605-12.

3. Lomax S, Qureshi A. Unusually early onset of post-dural puncture headache after spinal anaesthesia using a 27G Whittacre needle. Br J Anaesth 2008: 100 (5): 707-8.

4. Turnbull DK, Shepherd DB. Post-dural puncture headache: pathogenesis, prevention and Treatment. Br J Anaesth 2003; 91: 718-29.

5. Waise S, Gannon D. Reducing the incidence of post-dural punture headache. Clinical medicine 2013 (13); 1: 32-4.

6. Nath G, Subrahmaayam M. Headache in a parturient: Pathophysiology and management of post dural punture headache. Journal of Obstetric Anaesthesia and Critical Care 2011 (1); 2: 57-66. 


\section{AUTHORS:}

1. C. B. Sridhar

2. K. Shoba

\section{PARTICULARS OF CONTRIBUTORS:}

1. Associate Professor, Department of Anaesthesia, Saveetha Medical College.

2. Associate Professor, Department of Otorhinolaryngology, Saveetha Medical College.

\section{NAME ADDRESS EMAIL ID OF THE} CORRESPONDING AUTHOR:

Dr. C. B. Sridhar,

Shanthi Health Centre,

Sembulivarum, Chennai-600057.

E-mail: dr.c.b.sree9792@gmail.com

Date of Submission: 05/01/2015.

Date of Peer Review: 06/01/2015.

Date of Acceptance: 22/01/2015.

Date of Publishing: 02/02/2015. 